\title{
Analysis of the operation characteristics of a selected wind power plant
}

\author{
Karol Tucki ${ }^{1, *}$, Anna Bączyk $^{2}$, Izabela Wielewska ${ }^{3}$, and Michat Piątkowski ${ }^{1}$ \\ ${ }^{1}$ Warsaw University of Life Sciences, Department of Production Organization and Engineering, Nowoursynowska Street 164, \\ 02-787 Warsaw, Poland \\ ${ }^{2}$ Warsaw University of Life Sciences, Department of Hydraulic Engineering, Nowoursynowska Street 159, 02-776 Warsaw, Poland \\ ${ }^{3}$ UTP University of Science and Technology in Bydgoszcz, Department of Agronomy, Fordońska Street 430, 85-790 Bydgoszcz, Poland
}

\begin{abstract}
The purpose of this paper was to analyse the operation of a wind farm and the wind turbine yields with a total capacity of $46.5 \mathrm{MW}$. The analysis was divided into two stages: (1) the general characteristics of the facility, which included: a) distribution of wind speeds and the method of calculation and visualisation of the estimated electricity production, b) evaluation of the wind farm operation as per type of tested turbine and the wind farm terrain and (2) the impact of the facility on the quality of electricity in the distribution network.
\end{abstract}

\section{Introduction}

Wind energy in Poland is a dynamically developing sector of renewable energy sources [1-12]. Currently, the installed capacity in the wind farms alone is almost 6 $\mathrm{GW}$, which is about $14 \%$ of the power installed by domestic power plants $[13,14]$. Wind conditions in the country have forced the development of investments mainly in the north-western part of the country. However, in many other regions, the landscape is also diversified by revolving rotors. The nearest future of investment in wind energy in Poland is shifting to the Baltic Sea, where large private and public companies plan to invest in MW offshore wind farms [15-20].

The most important advantage of wind energy is the fact that wind is a source of renewable energy that will never run out, unlike such raw materials as gas or coal, the ability to gain partial independence from electricity suppliers and a significant reduction of pollution. According to calculations, by replacing coal power plants with wind farms we could reduce the emission of carbon dioxide $(700 \mathrm{~g} / \mathrm{kWh})$, nitrogen oxides $(4.2$ $\mathrm{g} / \mathrm{kWh}$ ), sulphur dioxide $(5.5 \mathrm{~g} / \mathrm{kWh})$ and dust (49 $\mathrm{g} / \mathrm{kWh}$ ) [21]. However, wind power has a significant disadvantage, i.e. unpredictable electricity production as a consequence of wind speed variability.

The purpose of this paper was to analyse the operation of a wind farm and the wind turbine yields with a total capacity of $46.5 \mathrm{MW}$. The analysis was divided into two stages: (1) the general characteristics of the facility, which included: a) distribution of wind speeds and the method of calculation and visualisation of the estimated electricity production, b) evaluation of the wind farm operation as per type of tested turbine and the wind farm terrain and (2) the impact of the facility on the quality of electricity in the distribution network.

\section{Materials and methods}

This article is based on data originating from a company operating in the private sector. Accordingly, all data contained herein constitute a trade secret. Therefore, any information subject to industrial property rights and copyright, as well as any other information that could potentially lead to the identification the farm described herein has been intentionally omitted. At the same time, it should be emphasised that the paper is based on actual studies from different periods of operation of the farm, as well as data originating from project analyses. In this paper, the original name of the wind farm was replaced by the abbreviation WF, and the wind turbines composing the wind farm - the abbreviation WT(s), with the relevant index - A and B, for two types of generating units.

The wind farm in question covers an area of over 40 $\mathrm{km}^{2}$ and is one of the largest facilities of this type in Poland. Its basic parameters are composed by (Fig. 1):

1) 12 turbines with a unit nominal power of $2 \mathrm{MW}$ and a hub height of $105 \mathrm{~m}$ and a rotor diameter of $100 \mathrm{~m}$,

2) 15 turbines with a unit nominal power of $1.5 \mathrm{MW}$ and a hub height of $80 \mathrm{~m}$ and a rotor diameter of $82 \mathrm{~m}$.

The total installed capacity of the units is $46.5 \mathrm{MW}$. Each turbine is equipped with a transformer increasing the voltage to $30 \mathrm{kV}$ and connected to the main distribution point, R-30 kV. The final power output runs through a $115 / 30 \mathrm{kV}$ block transformer over a $110 \mathrm{kV}$ overhead line to the national power grid. The ratings of each turbine are shown in Tab. 1.

An important element of the WF (Wind Farm) equipment is a measuring mast with five wind speed sensors and two weather vanes placed at a height of about 30 to $60 \mathrm{~m}$ above the ground level. In addition, each wind turbine has an anemometer and a weather

Corresponding author: karol tucki@sggw.pl 
vane installed at the top of the gondola. Weather analyses are carried out on a continuous basis during the operation of the wind farm. The expected service life of the facility is 20 years.

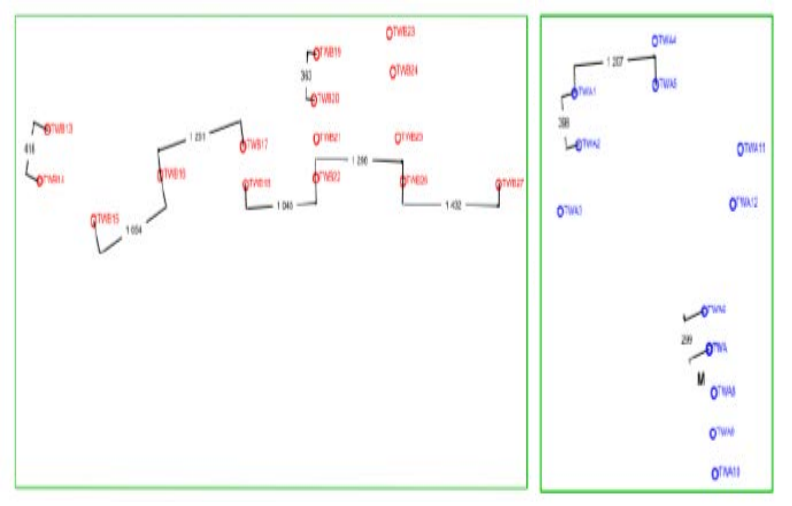

Fig. 1. Overview of a wind farm plan.

Table 1. Ratings of the most important elements of WTs.

\begin{tabular}{|c|c|c|}
\hline Parameter & WT A & WT B \\
\hline $\begin{array}{l}\text { Number } \\
\text { turbines }\end{array}$ & 12 & 15 \\
\hline Min. wind speed & $3 \mathrm{~m} / \mathrm{s}$ & $3 \mathrm{~m} / \mathrm{s}$ \\
\hline Max. wind speed & $22 \mathrm{~m} / \mathrm{s}$ & $25 \mathrm{~m} / \mathrm{s}$ \\
\hline Capacity & $2.000 \mathrm{~kW}$ & $1.500 \mathrm{~kW}$ \\
\hline $\begin{array}{l}\text { Operating } \\
\text { temperature }\end{array}$ & $-20^{\circ} \mathrm{C}$ to $+45^{\circ} \mathrm{C}$ & $-30^{\circ} \mathrm{C}$ to $+40^{\circ} \mathrm{C}$ \\
\hline $\begin{array}{l}\text { Standard (wind } \\
\text { class) }\end{array}$ & IEC IIb & IEC IIa \\
\hline $\begin{array}{l}\text { Diameter of the } \\
\text { rotor }\end{array}$ & $100 \mathrm{~m}$ & $82 \mathrm{~m}$ \\
\hline Rotation area & $7.854 \mathrm{~m}^{2}$ & $5.289 \mathrm{~m}^{2}$ \\
\hline Type & $\begin{array}{l}\text { Three degrees; } \\
\text { two planetary } \\
\text { segments and one } \\
\text { screw segment }\end{array}$ & $\begin{array}{l}\text { Three degrees; } \\
\text { one planetary } \\
\text { segment and two } \\
\text { screw segments } \\
\end{array}$ \\
\hline Hub height & $105 \mathrm{~m}$ & $80 \mathrm{~m}$ \\
\hline Frequency & $50 / 60 \mathrm{~Hz}$ & $50 / 60 \mathrm{~Hz}$ \\
\hline Type & $\begin{array}{l}\text { 4-pole }(50 \mathrm{~Hz}) / 6- \\
\text { pole }(60 \mathrm{~Hz}) \\
\text { generator with } \\
\text { dual power supply }\end{array}$ & $\begin{array}{c}\text { 6-pole }(60 \mathrm{~Hz}) \\
\text { generator with } \\
\text { dual power supply }\end{array}$ \\
\hline Voltage & $690 \mathrm{~V}$ & $12.000 \mathrm{~V}$ \\
\hline Rotation speed & 9-17 rpm & $16,7 \mathrm{rpm}$ \\
\hline Power $[\mathrm{kV} \cdot \mathrm{A}]$ & 2100 & 1700,350 \\
\hline Transmission [kV] & $30 / 0.69$ & $30 / 12$ \\
\hline Weight & $70 \mathrm{t}$ & $67.5 \mathrm{t}$ \\
\hline Hub height & $5.4 \mathrm{~m}$ & $4.1 \mathrm{~m}$ \\
\hline Length & $10.4 \mathrm{~m}$ & $8.7 \mathrm{~m}$ \\
\hline Width & $3.5 \mathrm{~m}$ & $3.4 \mathrm{~m}$ \\
\hline Starting point & $3 \mathrm{~m} / \mathrm{s}$ & $3 \mathrm{~m} / \mathrm{s}$ \\
\hline Switching point & $22 \mathrm{~m} / \mathrm{s}$ & $25 \mathrm{~m} / \mathrm{s}$ \\
\hline $\begin{array}{l}\text { Rated operating } \\
\text { point }\end{array}$ & $12.5 \mathrm{~m} / \mathrm{s}$ & $13.5 \mathrm{~m} / \mathrm{s}$ \\
\hline
\end{tabular}

Analysing the distribution of domestic wind energy resources, the WF is located in the third (III) wind zone, on a five-point scale, and the conditions are regarded as favourable [18]. The average annual wind speed in the area of location of wind turbines is $2.8 \mathrm{~m} / \mathrm{s}$. The strongest winds occur in November reaching an average speed of $3.4 \mathrm{~m} / \mathrm{s}$, while the lowest winds occur in August, with an average speed of $2.2 \mathrm{~m} / \mathrm{s}$. The most frequent wind direction of the WF location is from the west $(22 \%)$.

\section{Results}

Data analysis was carried out on the basis of measurements taken in the period from 1 February to 30 March 2011. The data from the C-1 and C-5 anemometers and the A-1 weather vane were used. The calculations were made for the whole wind power plant complex on the basis of the WF power curve (Fig. 2). The altitude was assumed for the gondola of $\mathrm{WT}_{\mathrm{B}}$, i.e. $80 \mathrm{~m}$ above the ground level.

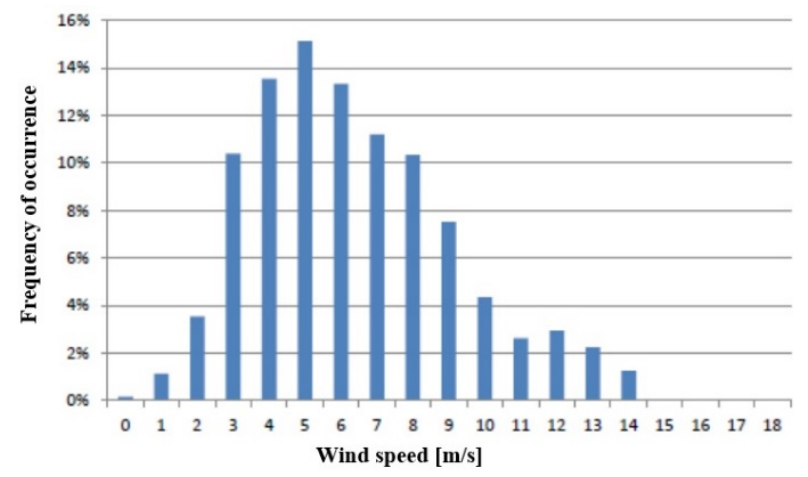

Fig. 2. Distribution of wind speed in the period from 1 February to 30 March 2011.

It can be observed that the prevailing speeds range from 3 to $8 \mathrm{~m} / \mathrm{s}$. They generate approx. $50 \%$ of the nominal gross power according to the information from the power curve of the WF (Fig. 4). Based on the power curve measurement data for the entire $\mathrm{WF}$, the total amount of energy produced by the WF, on the assumption of continuous trouble-free operation of all units, would be $27.3 \mathrm{GW} \cdot \mathrm{h}$. The wind, most frequently blowing from the west, would generate almost $8 \mathrm{GW} \cdot \mathrm{h}$. If divided into individual types of wind farms, $\mathrm{WT}_{\mathrm{A}}$ would generate about $15 \mathrm{GW} \cdot \mathrm{h}$, and $\mathrm{WT}_{\mathrm{B}}-12 \mathrm{GW} \cdot \mathrm{h}$ (Fig. 3).

On the basis of the data of power production by individual turbines, an analysis of energy efficiency was carried out taking into account characteristic features of distribution in the field, the value of energy produced and the model of the turbine.

Wind farm production in May 2016 (Fig. 4) was not among the highest. You can observe relatively equal energy production by each WT of a given type, which indicates full availability of the turbines. The left side of the graph shows the values of energy produced by 12 $\mathrm{WT}_{\mathrm{A}}$ type of turbines $\left(\mathrm{WT}_{\mathrm{A}}-\mathrm{W}\right.$ ind Turbine type $\left.\mathrm{A}\right)$. The discrepancies in results are due to the degree of production by the turbines of the same type, which can be understood when analysing the topography of the area and the configuration of the distribution of the generating units. 


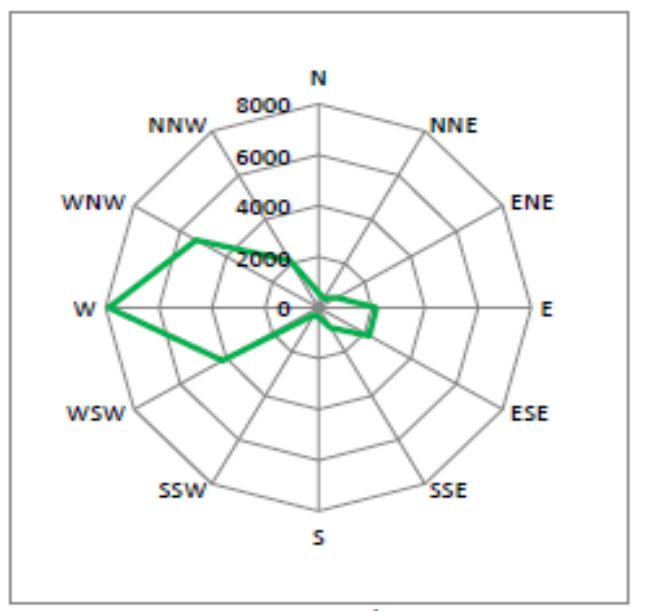

Fig. 3. Distribution of energy - Power rose.

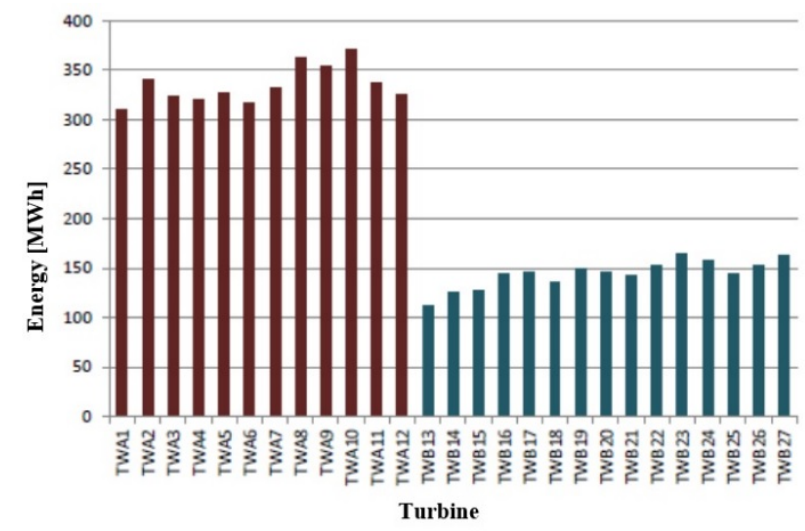

Fig. 4. Total amount of gross power generated by a single turbine in May 2016.

The first analysis was based on a test report verifying compliance with the parameters contained in the Distribution Grid Operating and Maintenance Manual (Grid Code - IRiESD). The manual describes in detail technical requirements for connecting the WF to the transmission network, and it is the operator's responsibility to present this report in the first year of operation of the WF.

The test aims to determine the power characteristics of the WF as a function of wind speed (WTs - Wind Turbine speed). The result will help to determine:

- the minimum wind speed at which WF and the individual WTs A and WTs B groups will start generating power,

- the minimum wind speed at which WF and the individual WTs A and WTs B groups will reach nominal power,

- the maximum wind speed at which WF and the individual WTs A and WTs B groups will shut down due to technical possibilities.

Observations were made for 320 days with full availability of turbines.

On the basis of the registered data, characteristics of the gross power capacity were determined for the whole wind farm (Fig. 5).
Based on the results of the data recorded during the observation of the WF, in the free operation mode, it is estimated that:

- the maximum gross power that the WF generates is approx. $47 \mathrm{MW}$,

- the minimum wind speed at which WF starts to operate is $\mathrm{v} \approx 3.5 \mathrm{~m} / \mathrm{s}$,

- the minimum wind speed at which WF reaches its nominal power is $\mathrm{v} \approx 14 \mathrm{~m} / \mathrm{s}$. Above this speed, the nominal power of the WF is maintained most accurately. With the wind blowing at the speed of:

a) $v=3.5-7.5 \mathrm{~m} / \mathrm{s}$, the characteristics change nonlinearly from 0 to $21 \mathrm{MW}$,

b) $\quad \mathrm{v}=7.5-9.5 \mathrm{~m} / \mathrm{s}$, a linear change in the characteristics was adopted, ranging between 21-38.5 MW,

c) $\quad \mathrm{v}=9.5-13 \mathrm{~m} / \mathrm{s}$ again, the characteristics change nonlinearly from 38.5 to $47 \mathrm{MW}$,

d) $\mathrm{v}>13 \mathrm{~m} / \mathrm{s}$ the characteristics curve is linear, with a constant power of $47 \mathrm{MW}$.

During the trial, turbines were not shut down due to any technical limitations caused by the maximum wind speed.

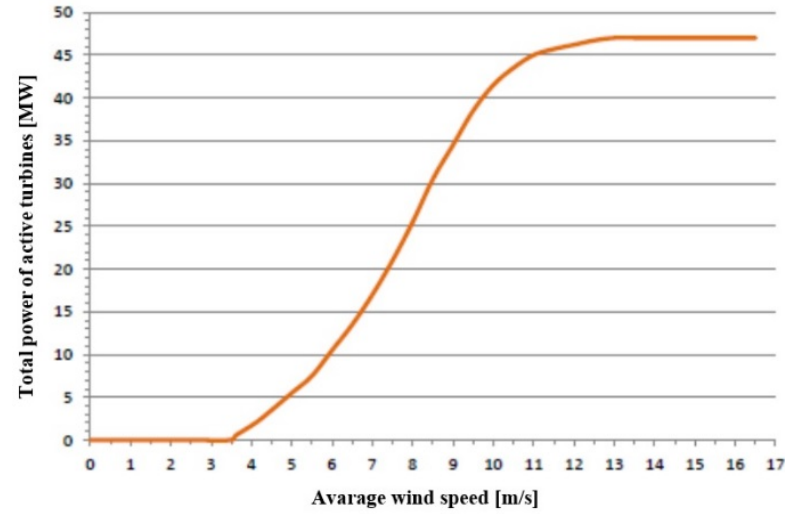

Fig. 5. Characteristics of the WF gross power as a function of wind speed.

As required by the DSO (Distribution System Operator), WFs must maintain power quality standards as a prerequisite for proper operation of wind farms. This is related to compliance with criteria defined in the Grid Code.

The quality of electricity was evaluated by analysing the measurements at the WF power output (GPZ R-110 $\mathrm{kV}$ ). Reference was made to the following results: voltage, current, active and reactive power on the 110 $\mathrm{kV}$ line, asymmetry of voltages and currents, higher voltage harmonics and the resulting $\mathrm{THD}_{\mathrm{U}}$ voltage distortion coefficient.

Based on an hour-long measurement of grid parameters, in which a free operational mode, shutdown, start-up and downtime of the WF were simulated, no sudden changes or surges in the voltage in excess of $3 \%$ at the WF connection point were observed. Neither were there any cyclical disturbances (Fig. 6). The maximum distortion of the $\mathrm{THD}_{\mathrm{U}}$ coefficient (THD - Total Harmonic Distortion), over $99 \%$ of the observation time, did not exceed 2\%. Accordingly, it may be 
concluded that the operation of the WF does not have a significant impact on voltage distortions.

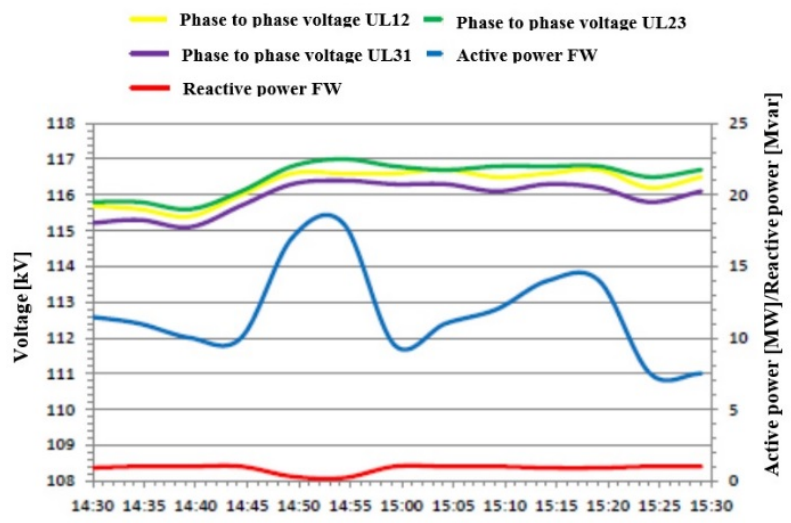

Fig. 6. GPZ R-110 kV. Effective voltage values as well as active and reactive power in the one-hour registration period.

The following characteristics (Fig. 7) shows the minimum voltage values due to a short circuit in the grid, for which the WF should remain in operation and allow for improvement of voltage conditions. In order to analyse the requirements, a reference must be made to the technical documentation for both types of turbines. When analysing the WTs technical documentation, it can be concluded that both types of turbines meet the Grid Code requirements in terms of occurrence of disturbances in the National Power Grid in the form of short-circuits.

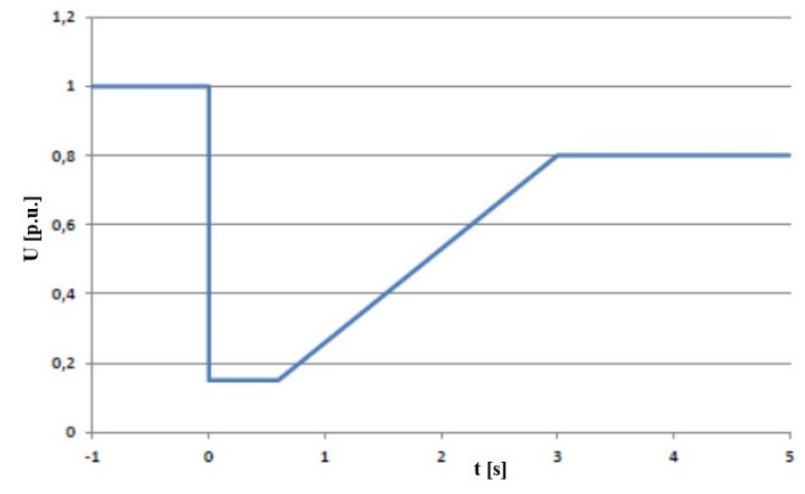

Fig. 7. Characteristics of the required WF operating range in case of network disturbances.

Another analysis was an attempt to verify changes in active power during the suspension of the free operating mode of the WF and the launch of the free operating mode of the WF. In addition, the WF's demand for active and reactive power was verified after all turbines were stopped.

The values recorded during the test trial are shown in Fig. 8. A zero production value of active power PSP $=0$ MW was set, which caused a sequential shutdown of the wind turbines. The setting was executed when the measured active power value at the connection point was determined (approx. 12.5 MW - on the axis of the graph - 60\%). The $0 \mathrm{MW}$ value was obtained after 4.5 minutes with an average gradient of $2.85 \mathrm{MW} / \mathrm{min}$. During the programmed shutdown, the maximum active power consumption of the WF was $\mathrm{PWF}=-0.83 \mathrm{MW}$, while the reactive power fluctuated at $\pm 1 \mathrm{M}_{\mathrm{var}}$. The behaviour of the WTs should be noted, which involved cyclic, temporary switching on and off of some of them, in order to compensate for the WF's active power demand and obtain the highest accuracy of limitation of the generation to the set active power PSP $=0 \mathrm{MW}$.

The launch consisted in restoring the WF to free operating mode. The generated power with an average gradient of $3.09 \mathrm{MW} / \mathrm{min}$ reached $18 \mathrm{MW}$, which was due to the then-current wind conditions.

Due to the inability, at the level of the SCADA system, to simultaneously discontinue the operation of all WTs, the WF demand for active power test was carried out along with the trial test of the WF's behaviour, i.e. reaction to frequency changes.

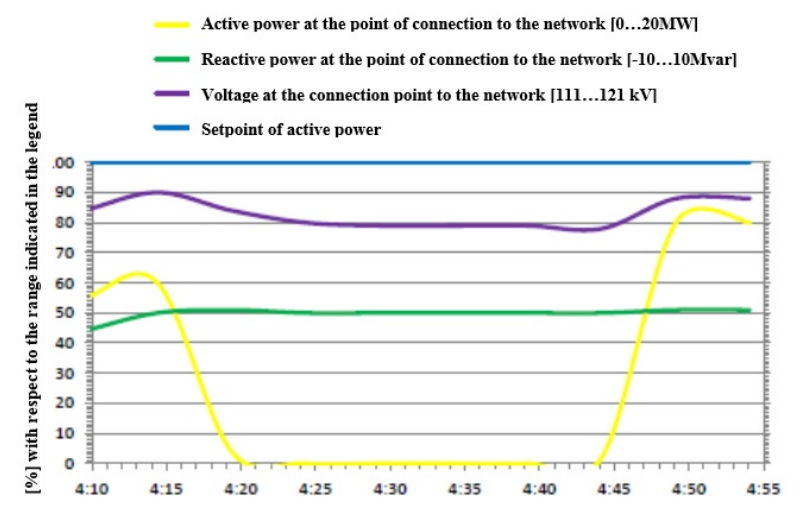

Fig. 8. Progress of the programmed trial of shutting down and starting the WF using the SCADA system.

What is significant importance about the test, is its option to discontinue the operation of the WF by the task of limiting the production of active power. Reactive power during the suspension of the operation of the WF at the point of connection to the National Power System was at the level of QWF $=0 \mathrm{M}_{\mathrm{var}}$. The WT was switched on and off during the test in order to balance power for the WF's own needs. The Grid Code requires a maximum of $30 \% \mathrm{Pn} / \mathrm{min}$ in terms of the average gradient of power changes, which in the case of the analysed WF results in values below $13.95 \mathrm{MW} / \mathrm{min}$. These requirements were met both for the suspension and start-up phase of the operation of the WF.

Following the trial tests, the case where the WF's power output was controlled during intervention work was examined (Fig. 9). Intervention work is a service provided by the WF to the National Power System in order to ensure real-time balance and management of active and reactive power flows. The purpose of such analysis is to verify the ability of the WF to maintain the set values of active power and to determine the rate of change of such set values.

The trial was initiated during free operation, with full availability of WTs. The wind speed provided good conditions for generating active power at about $17 \mathrm{MW}$. The active power generation limits were set in the following order: 


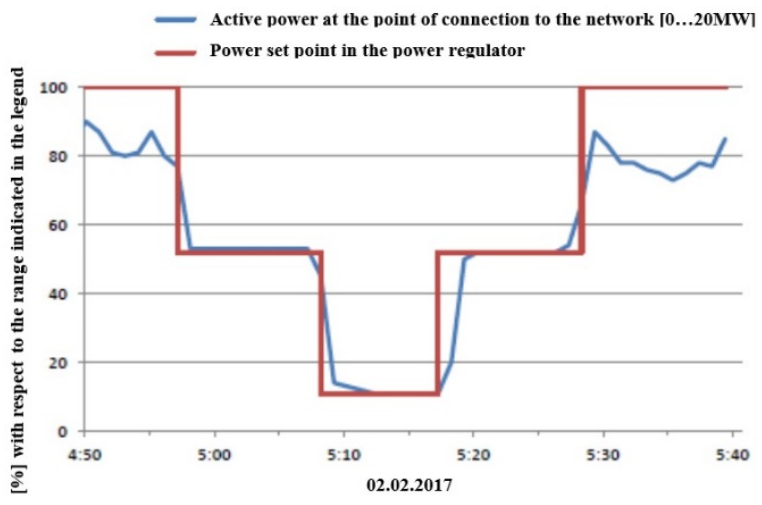

Fig. 9. Operation of the active power regulator of the WF during interventional work $\mathrm{PSP}=46.5 \mathrm{MW} \rightarrow 10.5 \mathrm{MW} \rightarrow$ $2.3 \mathrm{MW} \rightarrow 10.5 \mathrm{MW} \rightarrow 46.5 \mathrm{MW}$.

The characteristics (Fig. 9 ) show slight deviations of active power values from the set value in the controller. The maximum deviations of the measured active power values were observed for the set PSP value $=2.3 \mathrm{MW}$ and amounted to $-7.4 \% \mathrm{P} \mathrm{SP}$. The criterion of accuracy in maintaining the set value was $5 \%$, which resulted in the excess of $-55 \mathrm{~kW}$. The average gradients of changes were as follows:

- $11.1 \mathrm{MW} / \mathrm{min}$ during intervention lowering of active power from $46.5 \mathrm{MW}$ to $10.5 \mathrm{MW}$,

- $8.59 \mathrm{MW} / \mathrm{min}$ during intervention lowering of active power from 10.5 MW to 2.3 MW.

Next, the WF's reaction to frequency changes during free operation were tested. Due to the limitations of the control system, the test was carried out independently for two types of turbines - $\mathrm{WT}_{\mathrm{A} 1-12}$ and $\mathrm{WT}_{\mathrm{B} 13-27}$. During the test, the wind conditions enabled active power production outputs in the following ranges:

- $\mathrm{WT}_{\mathrm{A}}: \mathrm{PFW} \approx 22-45 \% \mathrm{PN}$, i.e. $10-21 \mathrm{MW}$,

- $\mathrm{WT}_{\mathrm{B}}: \mathrm{PFW} \approx 15-22 \% \mathrm{PN}$, i.e. $7 \mathrm{MW}$.

In the free operating mode, changes in the frequency received by the $\mathrm{WT}_{\mathrm{A}} \mathrm{SCADA}$ system were simulated, with the $\mathrm{WT}_{\mathrm{B}}$ and the $\mathrm{WT}_{\mathrm{B}}$ SCADA switched off, with the $\mathrm{WT}_{\mathrm{A}}$ switched off. In both cases, the range of frequency changes was $47.5-51.6 \mathrm{~Hz}$ according to the following values:

$$
\begin{gathered}
f_{\text {sym }}=47.5 \mathrm{~Hz} \rightarrow 50 \mathrm{~Hz} \rightarrow 50.6 \mathrm{~Hz} \rightarrow 51 \mathrm{~Hz} \rightarrow 50.6 \mathrm{~Hz} \rightarrow 51.6 \\
\mathrm{~Hz} \rightarrow 51 \mathrm{~Hz} \rightarrow 50,4 \mathrm{~Hz} \rightarrow \text { end of simulation }
\end{gathered}
$$

The reduction of power as a function of frequency is set in accordance with the parameters stated in the Grid Code. During free operation, the reference power is equal to the set power, and when the frequency increases above $50.4 \mathrm{~Hz}$ - in accordance with the applicable limits. Frequency changes in the fsym range $=47.5-50.5 \mathrm{~Hz}$ do not cause disturbances in the operation of the WTA turbines (Fig. 10) and they continue to generate power at a level resulting from wind conditions. An increase in frequency above $50.5 \mathrm{~Hz}$ results in a reduction of the power produced in proportion to the frequency obtained, until the turbines are completely shut down at the 51.5 $\mathrm{Hz}$ limit frequency. When assessing the rate of power change, the high accuracy of the response of the $\mathrm{WT}_{\mathrm{A}}$ turbines can be observed. The turbines automatically resumed operation at a simulated frequency fsym $=51$ $\mathrm{Hz}$.

In case of $\mathrm{WT}_{\mathrm{B}}$ turbines (Fig. 11), the response structure to changes in the simulated frequency value is similar to that of the $\mathrm{WT}_{\mathrm{A}}$ turbines. However, the instantaneous power value, given the applicable limitations, is characterised by clear deviations.

Both types of turbines of the FW comply with the Grid Code requirements related to changes in the generated power in connection with frequency changes. It is assumed that the accuracy of power adjustment by the $\mathrm{WT}_{\mathrm{B}}$ turbines could have been affected by unstable wind conditions during the test.

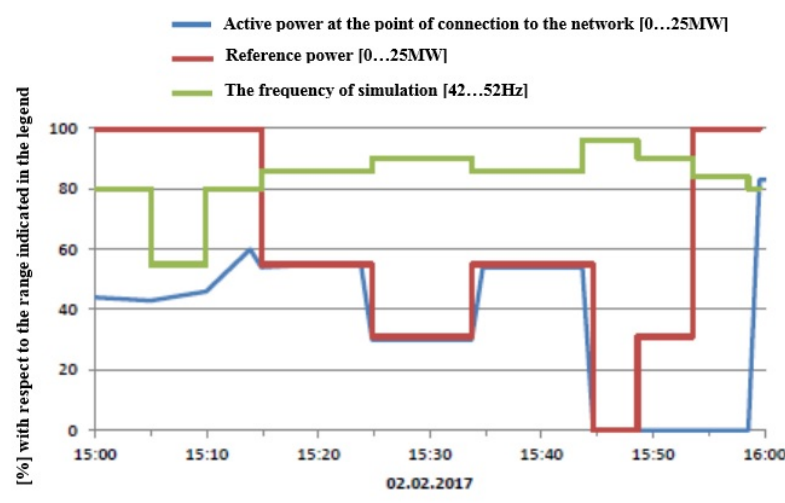

Fig. 10. Generation of active power by $\mathrm{WT}_{\mathrm{A}}$ during the response test of the WF on frequency changes with inactive $\mathrm{WT}_{\mathrm{B}}$.

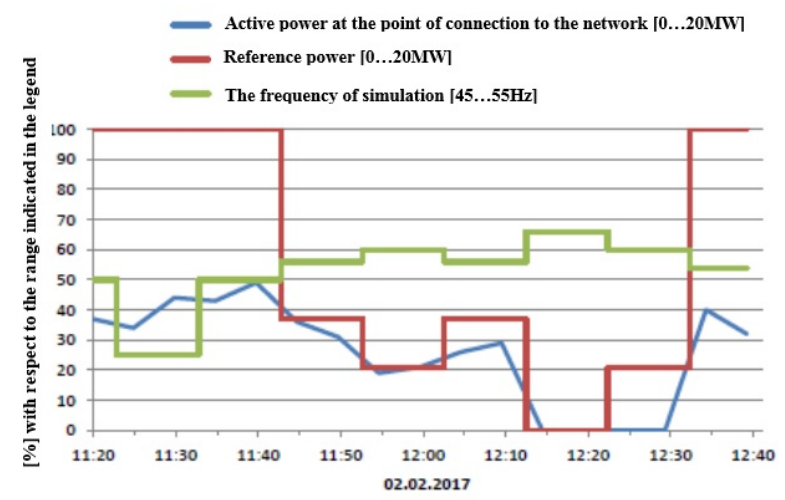

Fig. 11. Generation of active power by $\mathrm{WT}_{B}$ during the response test of the WF on frequency changes with inactive $\mathrm{WT}_{\mathrm{A}}$.

Another simulation consisted in verifying the dynamics and accuracy of the WF reactive power adjustment system and the evaluation of changes in the voltage value under the influence of reactive power adjustment. Changes in the reactive power value were set, and their values were read from, the recording device at the point of connection to the grid. The initial value of the set reactive power was $0 \mathrm{M}_{\mathrm{var}}$, and then changed as follows:

$$
\begin{gathered}
\mathrm{QSP}=+3 \mathrm{M}_{\mathrm{var}} \rightarrow+4 \mathrm{M}_{\mathrm{var}} \rightarrow-3 \mathrm{M}_{\mathrm{var}} \rightarrow-4 \mathrm{M}_{\mathrm{va}} \mathrm{r} \rightarrow \\
-4,5 \mathrm{M}_{\mathrm{var}} \rightarrow+10,6 \mathrm{M}_{\mathrm{var}} \rightarrow-10,6 \mathrm{M}_{\mathrm{var}} \rightarrow 0 \mathrm{M}_{\mathrm{var}}
\end{gathered}
$$


With the set power adjustment range, results with an accuracy not exceeding $\pm 5 \%$ were read from the recording device. As shown in Fig. 12, after the set point was achieved, the system was able to maintain the reactive power generation. The overshoot amplitude depends on the pitch of the change, e.g. ranging between +3 and $+4 \mathrm{M}_{\mathrm{var}}$, and -3 and $-4 \mathrm{M}_{\mathrm{var}}$, and is insignificant. Over time, these changes were from 1 minute for small pitches, and up to 3 minutes with pitches above $10 \mathrm{M}_{\mathrm{var}}$.

The reactive power adjustment by the WF did not cause any significant voltage oscillations at the point of connection to the grid.

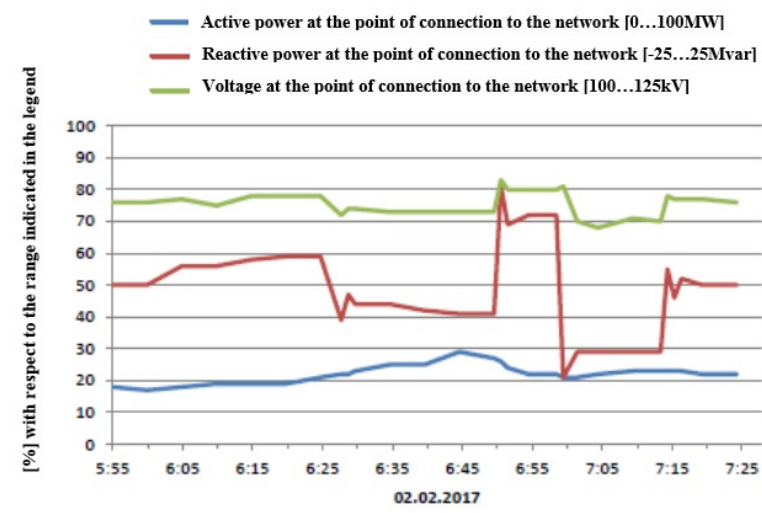

Fig. 12. Operation of the WF voltage regulation system operating in the reactive power adjustment mode.

The subsequent experiment consisted in verifying the dynamics and accuracy of the $\cos \varphi$ power coefficient of the adjustment system of the WF. In order to start the test, the $\cos \varphi \mathrm{SP}$ power coefficient adjustment mode was started. Next, in order to maintain the grid stability, the following operating steps were gradually introduced in the controller:

$$
\begin{gathered}
\cos \varphi \mathrm{SP}=1.0 \rightarrow 0.995 \mathrm{i} \rightarrow 0.985 \mathrm{i} \rightarrow 0.995 \mathrm{p} \rightarrow 1.0 \rightarrow \\
0.975 \mathrm{p} \rightarrow 0.975 \mathrm{i} \rightarrow 1.0
\end{gathered}
$$

The quality of adjustment is not satisfactory though (Fig. 13). Considerable adjustment failures and poor accuracy of maintenance of the desired power coefficient were found. The immediate WF's response to the changes was evident. With regard to the reactive power adjustment, the WF's reaction, in the form of voltage at the grid connection point, is significant. However, the Grid Code guidelines do not define the operating ranges of the $\cos \varphi$ power coefficient adjustment systems.

Visible changes in the voltage at the connection point have a marginal effect on the operation and quality of the SE.

During the simulation of the reactive power production by the WF, maximum capacitive and inductive reactive power values were obtained. The wind conditions enabled generation at the production level of active power in the range of $\mathrm{PWF}=32-39 \mathrm{MW}$. The set points resulting from wind speed have been introduced to the reactive power controller, i.e.:

- $\mathrm{Q}_{\mathrm{SP} 1}=-15.3 \mathrm{M}_{\mathrm{var}}$; during this time the active power generation was changed from $30 \mathrm{MW}$ to $39 \mathrm{MW}$,
- $\mathrm{Q}_{\mathrm{SP} 2}=+10.8 \mathrm{M}_{\mathrm{var}}$; during this time the active power generation was changed from $30 \mathrm{MW}$ to 37.5 MW.

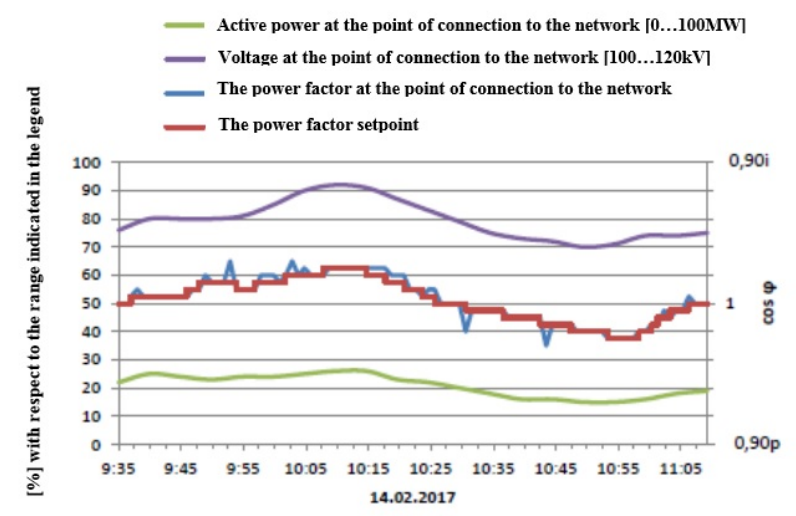

Fig. 13. Operation of the WF voltage regulation system operating in the power factor adjustment mode.

On the basis of the analysis, it was found that the $\mathrm{WF}$, irrespective of generated active power, has the ability to transmit and receive reactive power due to the value of the power $\cos \varphi$ coefficient of 0.975 at the level of (Fig. 14):

- $10.3 \mathrm{M}_{\mathrm{var}}$, with inductive grid load,

- $-10.3 \mathrm{M}_{\mathrm{var}}$ with capacitive grid load.

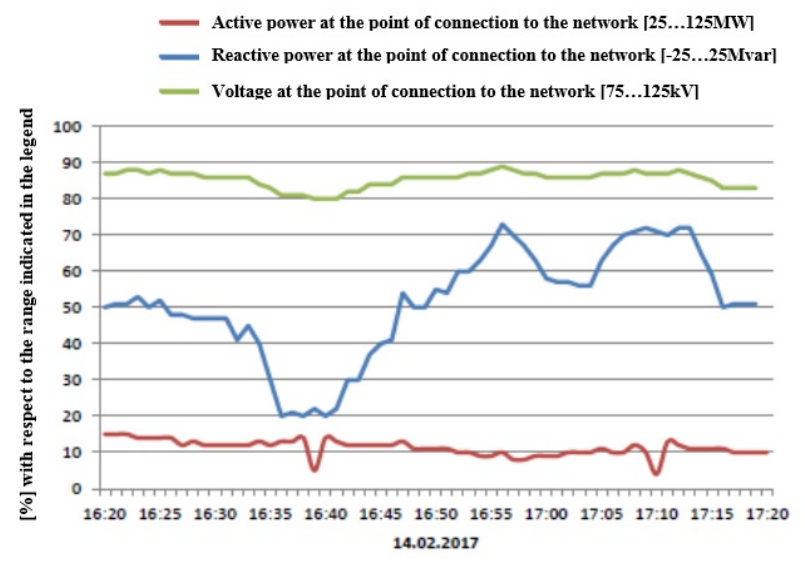

Fig. 14. Maximum reactive (capacitive and inductive) power generation process.

The values of reactive power at the point of grid connection during the test were maintained at $+10,6 \mathrm{M}_{\mathrm{var}}$ and $-15,3 \mathrm{M}_{\mathrm{var}}$.

\section{Conclusions}

Based on the tests, conclusions can be drawn in three directions: (1) conclusions resulting from the analysis of atmospheric conditions at the wind farm, (2) those resulting from the wind turbines distribution and (3) those resulting from the interpretation of the parameters of the wind farm's impact on the quality of electricity. With regard to the first group of factors:

1) The incidence of the prevailing direction of the wind has a decisive impact on the distribution of wind farms in the field. The turbines were arranged optimally 
with regard to the wind from the west and neighbouring directions.

2) The roughness of the terrain affects wind energy disturbances. Turbines were been placed in such a way as to minimise the impact of forestation, spatial development or natural unevenness of the area, on the generation of electricity.

3) Electricity production increases with increasing wind speed. For accurate calculations, the change in wind speed and altitude should be taken into account.

4) During the two-month wind measurement, the energy was calculated as $\mathrm{GW} \cdot \mathrm{h}$. The share in the calculated generation of $\mathrm{WT}_{\mathrm{A}}$ turbines was $56 \%$, and the remaining, i.e. $44 \%$ was attributable to $\mathrm{WT}_{\mathrm{B}}$.

5) The analysis of energy measurements generated in May 2016 shows that the share of $\mathrm{WT}_{\mathrm{A}}$ turbines of $65 \%$ in the total energy generation, and $35 \%$ in the case of $\mathrm{WT}_{\mathrm{B}}$, with power output of $6.18 \mathrm{GW} \cdot \mathrm{h}$. The highest production was obtained by the $\mathrm{WT}_{\mathrm{A} 10}$ turbine, generating $371 \mathrm{MW} \cdot \mathrm{h}$. The lowest value was obtained by the $\mathrm{WT}_{\mathrm{B} 14}-112$ turbine $-112 \mathrm{MW} \cdot \mathrm{h}$. It is estimated that such a poor result is influenced by the nearby forest which has an impact on the reduction of the mechanical wind energy quality.

Conclusions drawn from the distribution of the wind turbines:

1) Wind turbines are separated from the residential buildings at such a distance that the noise generated by the unit does not exceed $40 \mathrm{~dB}$. In practice, no turbine is closer than $1 \mathrm{~km}$ from the residential buildings.

2) With respect to the line of the most frequent wind direction, the wind farms were arranged so that the neighbouring farm was not in line in front of the previous one. The reason is to avoid the effect of aerodynamic shading - the wake effect. The $\mathrm{WT}_{\mathrm{B} 14}$ and $\mathrm{WT}_{\mathrm{B} 15}$ turbines - $860 \mathrm{~m}$ are arranged closest to each other in the western wind line. They are arranged in such a way so that the $\mathrm{WT}_{\mathrm{B} 14 \mathrm{c}}$ turbine does not "shade" the $\mathrm{WT}_{\mathrm{B} 15}$ turbine.

Summing up the results related to the parameters characteristic of the wind farm's impact on the quality of electricity, it can be concluded that:

1) The wind farm begins its generation with wind blowing at a speed of about $3.5 \mathrm{~m} / \mathrm{s}$. The nominal power is obtained at an approximate speed of $14 \mathrm{~m} / \mathrm{s}$. These values are similar to those declared by the manufacturer.

2) During the simulation of suspension and start-up of the wind farm, there were no sudden voltage surges exceeding acceptable limits. No other interference was observed.

3 ). The wind farm meets the requirements of the IRiESD (Grid Code) related to the resistance (ability to continue operation) of the farm at the occurrence of a short-circuit in the grid. In addition, the farm installation is properly secured and allows continuous movement of the rotors in the event of this type of disturbance. During a 1-second fault, both types of turbines lose their ability to operate smoothly when the mains voltage drops to 0 in the lower limit, and over $120 \%$ of the nominal voltage, in the upper limit.
4) All regulatory tests are characterised by high accuracy and do not cause adverse changes to the grid connection point.

Taking into account the evaluation of the cases under consideration, it can be concluded that the WF in question does not affect the stability of the grid. The detected fluctuations were not related to the operation of the WF.

It should be emphasised here that the majority of tests consisted in performing simulations, not actual parameter changes. It is justified and reasonable, and related to the least interference in the system of power grids and simultaneous conduct of reliable research in order to mitigate the risk of failure.

When met, the conditions for the output power of the $\mathrm{WF}$, do not allow for reflecting the full range of the analyses. The field tests allowed for the assessment of the WF adjustment capabilities as per the following variants: (1) start-up and discontinuation of the WF in free operating mode, (2) maintenance of the WF's operation in the event of a short circuit in the grid, (3) power adjustment in case of intervention work, (4) the WF's reaction to frequency changes, (5) voltage adjustment in the reactive power adjustment mode and the $\cos \varphi$ factor, (6) production capacity (transmission and consumption) of reactive power.

All the above operating modes and requirements for WFs have been assessed favourably. The wind farm has a beneficial effect on improving the quality of the grid. However, the essential parameter of the quality of operation of wind farms, that is their unpredictability, should be always considered.

\section{References}

1. R. Best, P.J. Burke, Energy Policy 118 (2018)

2. G. Dąbrowska, Elktro Info 1-2 (2018)

3. Z.Połecki, P. Kacejko, Rynek Energii 1 (128) (2017)

4. T. Popławski, M. Weżgowiec, Przegląd Elektrotechniczny 93 (2) (2017)

5. A. Augustyn, J.Kamiński, Rynek Energii 1 (134) (2018)

6. I.M. Łukasik, Rynek Energii 6 (97) (2011)

7. K. Badyda, H. Kapoń, Rynek Energii 3 (106) (2013)

8. A. Brzezińska-Rawa, J. Goździewicz-Biechońska, Renew and Sustain Energy Rev 38 (2014)

9. B. Igliński, R. Buczkowski, A. Iglińska, M. Cichosz, M. Plaskacz-Dziuba, Journal of Power Tech 95 (2) (2015)

10. J. Jurasz, P.B. Dąbek, B. Kaźmierczak, A. Kies, M. Wdowikowski, Energy 161 (2018)

11. J. Paska, T. Surma, Renew Energy 71 (2014)

12. A. Wędzik, T. Siewierski, M. Szypowski, Renewable and Sustainable Energy Reviews $\mathbf{7 5}$ (2017)

13. Mapa KSE. available at: www.pse.pl [07.09.2018] 
14. Moc zainstalowana $\mathrm{w}$ instalacjach wykorzystujących energię wiatru (stan na dzień 31.03.2018). available at: www.ure.gov.pl [09.07.2018]

15. A. Dobrzycki, G. Wodnicki, Poznan Uni of Tech Acad Jour. Electr Eng 94 (2018)

16. K. Międlarz, P. Więcławski, 2018. Zagadnienia Aktualnie Poruszane Przez Młodych Naukowców 12. CREATIVETIME, Kraków

17. B. Igliński, A. Iglińska, G. Koziński, M. Skrzatek, R. Buczkowski, Renew and Sustain Energy Rev 64 (2016)
18. A. Ostrowska, Annales Universitatis Mariae CurieSkłodowska. Sectio G. Ius 65 (1) (2018)

19. M.S. Maj, 2017. Offshore Wind Energy in Poland: Potential in Transformation of Polish Energy Sector. Engineer's Thesis. Warsaw University of Technology

20. M.M. Sokołowski, Energy Policy 106 (2017)

21. K. Kożuchowski, 2012 Meteorologia i klimatologia, Warszawa 